\title{
Research on the integrated design strategy of green building
}

\author{
Yang WANG ${ }^{1}$,Ping Qing ZHANG ${ }^{2}$ \\ ${ }^{1}$ Yantai Nanshan University Longkou, Shandong, China \\ ${ }^{2}$ Yantai Nanshan University Longkou, Shandong, China
}

\begin{abstract}
With the increasingly serious environmental problems, energy saving and environmental protection of the green building began to have people's attention, and gradually become the development trend of future building, which came into being green building integrated design. How to apply the integrated design theory of green building to the concrete architectural design practice is a question that designers must seriously think about. This paper expounds the integrated design concept of green building and integration methods from the connotation of green building design, and puts forward the integrated design strategy in the green building design concept in theory and practical application, in order to provide reference to the designers or managers.
\end{abstract}

Keyword: Green building;Integration;Design strategy

At present, the concept of green building has gradually been known and accepted by people, and increasingly become a rookie in the construction industry. However, according to the specific conditions, the reasonable design of green building, green building has been a major problem faced by the builders. Integrated green building design is the green building design in a very important part, through the use of aesthetics, architecture and other related disciplines of knowledge, combined with the building of the actual characteristics of, with the vision of the part and the whole, of Ministry of inside and outside the building of the various elements of the intrinsic link of analysis and integration, harmony in order to achieve with nature and architecture between the three.

\section{CONNOTATION OF GREEN BUILDING}

The green building, as the name suggests, is shown the concept of green building, and the green concept, in fact, have a very broad meaning, which is not only a vertical greening, roof garden or green plants a lot of architectural concept, but based on and harmless to the environment and natural resources make full use of the concept of a sustainable, ecological, energy saving and environmental protection building. In fact, the green building, the use of materials and interior decoration and overall design has a very high requirements, on the one hand, the need to ensure indoor layout is reasonable at the same time, by reducing the selection of synthetic materials, and make full use of sunlight, thereby saving energy loss. On the other hand, emphasizes the implementation of human, architecture and nature in a harmonious development requirements in the use of artificial means or behavior, create a comfortable, good life, the use of the environment at the same time, it will be possible to nature damage to the lowest.

Generally speaking, green building not only includes temperature, solar lighting, air quality indoor environment, or in the green environment, natural ventilation and other external environment, have a high demand. Of course, on the green building, it is a fundamental way to realize the strategy of sustainable development of our country, the implementation of green building concept is extremely urgent. 


\section{CONNOTATION OF GREEN BUILDING INTEGRATION DESIGN}

Between the integrated green building design is to achieve an important path of green building features, its position in the green building design, in ensuring the building body and the life at the same time, as far as possible according to the knowledge of related disciplines, from both the overall and local levels of, man, nature and construction of three harmony.

However, the design theory actually needs to carry on the guidance of certain design goals, in general, the main performance in target function, environmental objectives, and economic goals etc.

First, the green building integrated design and common building compared to higher, not only need to meet the basic functional requirements, but also should pay attention to environmental comfort considerations. In order to meet the requirements of this goal, building designers need to flexible use of physics, ergonomics and psychology knowledge.

Secondly, the integration of green building design is another important goal is the pursuit of environmental goals, in terms of energy use not only need to give priority to the use of renewable energy, but also should try to improve the utilization efficiency.

The end, the economic benefit of green building determines whether it can develop healthily and steadily, so it should be considered carefully in the process of green building design. That requires strict control of all aspects of the design, in the premise of ensuring the quality of the building, the maximum cost savings.

\section{INTEGRATION METHOD OF GREEN BUILDING DESIGN}

The main essence of integration is the scattered elements together, the different things of value of organic combine, make itself has no value or the value of the small things play a role in value, and ultimately the formation of value and efficiency as a whole. Green building integration has experienced many levels of integration, from disciplines to social systems integration, from small to large integration. Green building projects from the proposed to remove the whole life cycle should run through the concept of green. Including planning, design, construction, operation and management of the whole process of the completion of the whole process, the only way to be called a green building.

This paper only discusses the design phase of green building integrated design method. Integrated design is a design method and idea, to carry out a systematic research on construction can be by using the integrated design, through the relationship between the various elements of the building to achieve harmony between man and nature, through integrity, timing and association characteristics, this paper puts forward some corresponding solutions. Integrated design in the design concept, design technology, design and creative aspects of the new design concepts and design methods, to expand the scope of the architectural design.

\subsection{Manifestation of green building}

American architect Sim van der Ryan in his book "integration design," a Book of "integrated design" concept, gives the definition In 1981. He believes that the integration of design is in the construction process, according to the building environment, according to local conditions, the design and construction of housing, to reflect the harmonious unity of the building with nature, but also in his life.

Research, focusing from the point of view of the ecology of building with natural harmony and unity as the main research direction and the research goal, in the course of the study, he pays attention to the field of terrain and the local climate characteristics, can according to the terrain and geography climate design harmonious and comfortable building, in dealing with the problem, he is more from the ecological nature of thinking, find out problem-solving methods, such as how to deal with solid waste, construction waste, etc.

\subsection{Technology integration}

American architect Leonard R. Bachman mentioned in his book, "the integration of architecture and design elements of the system, a book, integration is a concept, is a way of thinking, architects are required to have this way of thinking, in the construction process to purpose and direction of architecture selection and combination, emphasize the complementary and technical design, he believes that the effective combination of the integration of technology and design, the integration will be subjective and sensory of harmony and unity, he will be the integration points for the integration of software and hardware integration of two parts.

\subsection{Method integration}

Germany's famous architect Thomas integrated design as a scientific design method to treat, he will be building research as an incentive, through the study of architectural design methods to find. Thomas believes that as a good architect needs to be curious about everything, architects should also have the scientist's thinking mode and on building full of imagination and creativity, and from the deep level of 
construction of analysis and research, to find effective methods for integrated building.

\section{PROBLEMS IN THE INTEGRATION DESIGN OF GREEN BUILDINGS}

\subsection{By the limitation of traditional design patterns}

By the current situation, China's design company or design institute basically are the traditional design mode are adopted, the staff is divided obviously, different design personnel responsible for the area is relatively independent, generally speaking, mainly planning, architecture, structure, equipment, etc. professional personnel, each design personnel to carry out their duties is responsible for their own area of work. For the problems in the work of communication and less, that involves a long cycle. This traditional model because of its own shortcomings so that it can better adapt to the development of green building.

\subsection{Collaborative decision making}

Through the existing architectural design patterns of substance analysis and past experience reference, using collaborative design and concurrent design of green building for the integrated design, the for reconstruction of the design process, the life cycle of green building and other aspects of the coverage is wide and contains the content is more extensive.

The architect plays a central role in connecting the whole team. Planning, building, structure, equipment and other professional construction information communication must be clear. Is divided into two forms, one is according to the professional order delivery; one is according to the inverse professional order feedback. In the design of the whole green building in the process of the existence of the problem of transmission and feedback more timely, there are contradictions in time to coordinate and solve. For example, the choice of bricks: Architects according to the green building concept, to determine the type of specifications to other professional designers. This brick must also meet all kinds of requirements of other professional. Other professional designers if there are different views in a timely manner to the architect. Will consult, adjust and ultimately determine the best solution to meet the requirements of the parties.

More frequent exchanges between designers and various professional work is not only the total transfer of information, even under incomplete information can also be their own work is carried out by the relevant information, this greatly, the product life cycle, saving more time and improve the work efficiency.

\section{INTEGRATED DESIGN STRATEGY OF GREEN BUILDING}

\subsection{Integration of developer factors}

Project development is a kind of market behavior, so the economic benefit will directly affect the overall level of development of green building, the developers factor is the cost factor, but the fundamental factor is the input-output ratio, which is benefit for our evaluation of the economic benefits of green building, the main from the amount of funds used, results of these two aspects of the problem analysis of the use of funds less, good results, it can be judged as excellent economic benefits in assessment of green building cost, not only from the pre cast cost calculation, while also taking into account the late sales value and the total life cycle, in the current environmental problems are becoming more and more severe form, the market value of green building is to constantly improve, starting from the long-term perspective, the most obvious advantage for green building is reflected in the use of the process of building can be seen in many Reduce operation and maintenance costs, save a huge amount of money at the same time, the market value is generally high non green building.

\subsection{Integrated of operator factors}

China's "green building evaluation standard of land, energy and water saving, material saving, indoor environment and operation of these six items in half will produce benefits in the later operation, can be said that the biggest beneficiaries of the current evaluation system for green building operations, however, due to the development of green building technology is late, compared with the traditional technology factors still exist such problems as difficult maintenance, easy to damage and difficult to debug, maintenance cycle is short, the use is not convenient, the actual efficiency low so the latter part of the integration operators should also consider more green building technology has the advantages of easy maintenance, easy maintenance, easy operation, high use maintenance performance, should play the designer's creativity, innovation, based on the existing green on the improvement of Technology. 


\subsection{Integrating of user factors}

China's "green building evaluation criteria in Chinese items of indoor environment is considered user factors and the specific provisions comprehensively consider the lighting, noise control, air quality and other factors, but on the current China's existing environmental problems is lack of consideration, integrating user factors to be considered in addition to the green building evaluation standard, basic requirements of indoor environmental requirements, should consider the healthy lifestyle, from the safety of drinking water, the actual air quality, waste disposal, environmental comfort aspects of further green design, green building become comfortable and healthy building, so as to enhance the market value

\subsection{Integrating and coordination balance}

Green building integrated design theory, the main consideration of the evaluation standard of green building, developers, operators, users factors factors factors of these four aspects, however, these four factors namely the ultimate interests of unity, even many contradictions and opposites, contradictions complex dialectical unity, the core task is to integrate the design theory in four big contradictions the factors to balance out a compromise best, let four factors to obtain a win-win situation which requires designers to gather four requirements in the entire design process, constant collision and modified design content, design, procurement, construction, commissioning, the use of five stages are needed to balance design

\section{INTEGRATED DESIGN STRATEGY OF GREEN BUILDING}

Amory. B. Lowens in the ideas from East and West fusion: sustainable development construction of overall design, this paper pointed out: green building contains very extensive, not only refers to the material side, including cultural, economic and spiritual needs. In the green building design, not only need to consider the natural lighting, solar power generation, sewage recycling and other factors, also need to involves the integration of the natural integration of the building and the surrounding environment in relation to man and nature, and many other aspects. With green building design specification GB /T50378 2006 requirements, the integrated application of green building design theory is summarized as follows: to meet the control; choose the general term; as far as possible the use of priority

\subsection{Sspace saving design}

Building itself is a commodity, and green building is a good product, to create economic benefits for their own at the same time improve people's quality of life, save the cost of production and living, improve economic efficiency. Green building design process, the project location should be in line with the principle of land, project location should be combined with specific urban and regional planning and meet the residential buildings per capita living index, and give full consideration to the rational development and utilization of the roof and the underground space.

\subsection{Energy saving, water saving, material saving design.}

Green building advocates a green, energy-saving, environmentally friendly architectural design. Therefore, we should pay attention to construction and the overall performance of traditional architecture compared to upgrade and fully pay attention to building the economic benefits, social benefits and environmental benefits of combining.

\subsection{Interior environment design}

Building good environment is the necessary conditions to ensure the normal life of the people, because reasonable light environment can not only reduce artificial lighting system energy consumption, but also effectively alleviate visual fatigue, and improve the comfort of people's lives.

In order to achieve the above purpose, now building design in green building design theory to guide the integration, on the one hand, in the use of solar light focusing on the shade, effective way to avoid direct sunlight glare phenomenon. On the other hand, when the lighting cannot meet the requirements of the building, the courtyard, the atrium for a simple processing to increase the amount of indoor lighting. At the same time, under the impetus of modern science and technology, some new technologies have been applied to the design of buildings, in order to achieve the purpose of improving the quantity of indoor lighting.

\section{CONCLUSION}

To sum up, have a certain understanding of the relevant aspects of our connotation of green building, green building and the importance of integrated design theory. From which we can deeply recognize, as a fully embodies the harmony between man and nature of green building and its specific construction up is not easy, in fact, whether it is in the integration of green building design theory or in the green building design theory of concrete operation, the need strictly in accordance with the internal and external 
environment and to a part and the whole, the whole and the part of visual concept, effectively achieve green goals. Anyway, we as the actual builders of green building should in the practical aspects of the work, and constantly strengthen their design knowledge, analyzing and summarizing the experience that will truly green building integrated design theory of utility to play to the maximum. 